\title{
De Columbine à Virgínia Tech: Reflexões com Base Empírica sobre um Fenômeno em Expansão
}

\author{
From Columbine to Virgínia Tech: Empirical Based Reflections about an Expanding \\ Phenomenon
}

\author{
Timoteo Madaleno Vieira*, Francisco Dyonísio Cardoso Mendes \\ \& Leonardo Conceição Guimarães \\ Faculdades Alfa/Universidade Católica de Goiás
}

\begin{abstract}
Resumo
O fenômeno conhecido como school shooting vem chamando a atenção do mundo, principalmente após a tragédia na Columbine High School, na cidade de Littleton, Colorado, nos Estados Unidos, em 1999. Posteriormente, em abril de 2007, o estudante Cho Seung-Hui protagonizou um massacre de proporções ainda maiores ao atirar contra estudantes do Virginia Polytechnic Institute and State University, matando 32 pessoas e se suicidando ao final. O presente artigo reflete sobre o fenômeno chamando a atenção para a sua expansão pelo mundo e traz uma reflexão, baseada em dados empíricos, sobre o desenvolvimento dos protagonistas dos massacres em seus contextos sociais, incluindo o ambiente familiar, a mídia e interações entre colegas nas escolas e universidades.

Palavras-chave: Ambientes sociais; Violência escolar; Bullying; Desenvolvimento psicossocial; Tiroteios nas escolas.
\end{abstract}

\begin{abstract}
School shooting phenomenon has attracted attention throughout the world, especially after the Columbine massacre in April, 1999. In that event, 12 people died and about 30 were hurt. Some years later, in April 2007, Cho Seung-Hui carried out an even more impressive deed, shooting and killing 32 people at Virginia Polytechnic Institute and State University, USA. This article presents school shooting as a growing phenomenon that may happen anywhere and not just in the United States. A reflection based on empirical research is presented focusing the development of school shooters in their social contexts, including home environment, media influence, and inter-students interactions in High Schools and universities.

Keywords: Social environments; School violence; Bullying; Psychosocial development; School shooting.
\end{abstract}

O filme "Tiros em Columbine", do documentarista norte-americano Michael Moore (2002) chama a atenção para um drama que vem deixando o mundo em estado de alerta. Trata-se do fenômeno conhecido, em termos gerais, como School Shooting (em uma tradução aproximada: tiroteios na escola). Os school shooters (os atiradores) algumas vezes deixam claro que seu alvo é a escola (instituição) e o que ela representa, bem como a própria sociedade da qual se consideram vítimas (Muschert, 2007).

Os autores Harding, Fox e Mehta (2002) se referem aos tiroteios nas escolas como rampage school shootings, diferenciando essa categoria de outras nas quais os atiradores não são estudantes ou não fazem parte da escola, e de eventos semelhantes em outros ambientes. Um exemplo do fenômeno em outros ambientes é o massacre ocor-

* Endereço para correspondência: Av. São João, 145, Vila Alto da Glória, Goiânia, GO, Brasil, CEP 74815-700.

E-mail: timoteo.psi@gmail.com rido em um cinema de São Paulo em 1999, no qual o estudante de medicina Mateus da Costa Meira atirou contra a platéia, matando três pessoas e ferindo outras quatro (Lima \& Zakabi, 1999). O termo rampage se refere a situações turbulentas envolvendo grupos de pessoas (ou multidões), e a expressão school shooting identifica que se trata de um tiroteio em um ambiente específico (a escola). O interesse por esse fenômeno cresceu muito nos últimos anos, principalmente após um evento específico.

Em abril de 1999, Erick Harris e Dylan Klebold entraram na Columbine High School onde eram alunos e abriram fogo, matando doze estudantes e um professor e ferindo mais de 30 outras pessoas (Clabaugh \& Clabaugh, 2005; Fjällström, 2007; Larkin, 2007; Lickel, Schmader, \& Hamilton, 2003). O desfecho do massacre se deu com o suicídio dos dois adolescentes. Nos dias seguintes à tragédia foram descobertas várias bombas espalhadas pela escola, que falharam em detonar. O objetivo de Harris e Klebold parece ter sido fazer um número ainda maior de vítimas. 
Durante quase oito anos o massacre perpetrado por Harris e Klebold era o que mais chocava a população mundial até que, na véspera do oitavo aniversário da tragédia de Columbine, no dia 19 de abril de 2007, algo ainda pior aconteceu. Cho Seung-Hui, um estudante sulcoreano radicado nos Estados Unidos, matou 32 pessoas, entre estudantes e professores da Virginia Polytechnic Institute and State University, e se suicidou em seguida. O rapaz enviou à rede de televisão norte-americana NBC um pacote contendo vídeos e fotografias, onde convoca todos os "fracos" a fazerem o mesmo que ele. Ele também faz referência a Columbine, citando Harris e Klebold como mártires e fazendo assim uma ligação entre os dois eventos (Marques, 2007).

Esse tipo de tragédia pode ser considerado por muitos como peculiarmente norte-americano, não havendo motivos para maiores preocupações pelo restante do mundo; todavia, entre Columbine e Virginia Tech o fenômeno ocorreu em vários países. Uma matéria jornalística do dia 22 de abril de 2007, publicada no site The Sunday Paper (Ramage, 2007) afirma que casos de school shooting ocorreram na Alemanha, na Suécia e no Canadá (para mais informações sobre school shootings em outros países, ver também Muschert, 2007).

Os pesquisadores Watson, Andreas, Fischer e Smith (2005) chamaram a atenção para fatores ambientais significativos para o desenvolvimento dos estudantes atiradores. O presente artigo assume viés semelhante, em oposição a compreensões deterministas do fenômeno. Enfatiza-se a necessidade de mais pesquisas em todo o mundo e de trabalhos preventivos com base nas informações já amplamente conhecidas.

\section{Ambiente Familiar e Desenvolvimento Psicossocial}

Alguns autores têm chamado a atenção para o fato de que problemas comportamentais apresentados na infância podem persistir na adolescência e na vida adulta, e que os pais e/ou cuidadores têm grande participação nesse processo (Gomide, 2000; Marler, Trainor, \& Davis, 2005; Watson et al., 2005). A Teoria dos Sistemas Ecológicos, de Urie Bronfenbrenner (1996), é uma teoria do desenvolvimento humano que considera a ecologia dos relacionamentos dentro dos sistemas ambientais dos quais a criança participa (Martins \& Szymanski, 2004). De acordo com essa teoria a família é o primeiro ambiente da criança, denominado microssistema. Dentro desse microssistema, as primeiras interações sociais ocorrem em forma de díades (mãe-filho, pai-filho, etc.). Com o passar do tempo essas relações vão se expandindo, permitindo à criança novas interações. $\mathrm{O}$ microssistema familiar é a maior fonte de afeto, segurança, proteção e bem-estar, proporcionando o importante senso de permanência e estabilidade nos primeiros anos de vida. $\mathrm{O}$ senso de permanência diz respeito à segurança de que os elementos centrais da experiência de vida são estáveis e organizados dentro das rotinas diárias familiares. A estabilidade se define pela segurança das relações entre pais e filhos, e pela expectativa de que mesmo em situações de estresse não haverá ruptura nos relacionamentos (Cecconello, Antoni, \& Koller, 2003). Assim, a ausência de interações saudáveis entre pais e filhos pode afetar o desenvolvimento das crianças e sua preparação para a vida social dos anos posteriores.

Cecconello et al. (2003), ao tratarem das interações dos pais com os filhos, fazem uma diferenciação entre estilos parentais e práticas educativas. As práticas educativas se referem a estratégias que os pais utilizam para atingir objetivos específicos relacionados a diferentes domínios, tais como o social, afetivo, acadêmico, etc. Essas práticas estão relacionadas a circunstâncias e contextos mais específicos. Já o estilo parental se refere ao padrão global característico das interações dos pais com os filhos manifesto nas mais diversas situações, e ao clima emocional gerado por tais interações.

O uso de punição física ou outras medidas punitivas abusivas pressupõem um estilo parental autoritário, o que parece prejudicar o desenvolvimento de crianças e adolescentes devido ao alto nível de controle e pobreza de afeto na maior parte das interações.

Outro estilo parental é o indulgente, no qual há uma combinação de baixo nível de controle com alta responsividade. Pais indulgentes são afetivos e comunicam-se bem com os filhos, porém não os monitoram e atendem prontamente às suas demandas, não estabelecendo regras e limites e estabelecendo pouca demanda de responsabilidade e maturidade. Já o estilo negligente é caracterizado pela falta de monitoramento dos filhos por parte dos pais, a ausência de regras claras a serem seguidas no ambiente familiar e o baixo nível de interação e de afetividade entre pais e filhos (Cecconello et al., 2003). O estilo indulgente e o negligente são marcados por pais que permanecem à distância em relação à rotina dos filhos, falhando em orientá-los acerca de seus comportamentos, crenças, expectativas, emoções, etc.

Em contrapartida, Cecconello et al. (2003) apresentam o modelo denominado autoritativo, que se diferencia tanto do modelo autoritário quanto do negligente e indulgente, caracterizando-se pela participação dos pais na vida dos filhos com regras claras e limites, combinados a interações afetivas adequadas. Há, neste estilo, alta demanda por responsabilidade e maturidade, além das demonstrações de afeto. Estudos apontam para bom nível de competência social, assertividade e comportamento independente de crianças; e também apontam melhores níveis de adaptação psicológica, competência social, autoestima, autoconfiança e menores níveis de problemas comportamentais, ansiedade e depressão na adolescência, relacionados ao estilo autoritativo em comparação com os outros estilos (Cecconello et al., 2003).

Além da relação dos estilos parentais com o desenvolvimento de crianças e adolescentes, é interessante observar uma possível tendência de reprodução dos estilos 
Vieira, T. M., Mendes, F. D. C. \& Guimarães, L. C. (2009). De Columbine à Virgínia Tech: Reflexões com Base Empírica sobre um Fenômeno em Expansão.

parentais aprendidos com os pais, ao longo de várias gerações (Marler et al., 2005).

\section{A Influência de Modelos Comportamentais Apresentados pela Mídia}

Estudos sobre os efeitos dos modelos apresentados pela mídia no comportamento de crianças têm mostrado que este é um fator significativo (e.g. Anderson \& Bushman, 2002; Batista, Fukahori, \& Haydu, 2004; Gomide, 2000; Vieira, 2007; Zavaschi, 1998).

Gomide (2000), se referindo a um relatório de 1985 da American Psychological Association, alerta para o fato de que crianças e adolescentes podem tornar-se menos sensíveis à dor alheia ou podem sentir-se amedrontados após a exposição a programas violentos na televisão. O relatório cita que programas infantis freqüentemente apresentam até vinte cenas contendo agressões, a cada hora.

Não se pode esquecer, ainda, que hoje são comercializados jogos nos quais é possível escolher desempenhar o papel do bandido ou do mocinho, como é o caso do jogo Counter-Strike, ou jogos em que o jogador recebe pontos por infringir algumas regras sociais importantes tais como regras de trânsito (incluindo pontuação para o jogador por atropelar pedestres) como é o caso do jogo Carmageddon (Alves, 2004). Apesar das tentativas de proibição de jogos dessa natureza, os mesmos são facilmente encontrados no mercado de produtos falsificados.

Os estudos realizados por Gomide (2000) e Gomide e Speranceta (2002) mostram que crianças pré-escolares podem apresentar aumento na frequiência de comportamentos agressivos imediatamente após terem sido expostas a filmes violentos com lutas. Esses resultados confirmam a hipótese da Teoria da Aprendizagem Social, apresentada por Albert Bandura (1979) de que observando um modelo e percebendo as conseqüências favoráveis que o ambiente fornece para os comportamentos apresentados, há uma alta probabilidade de que os comportamentos observados sejam aprendidos (Barr \& Hayne, 2003).

$\mathrm{O}$ estudo realizado por Batista et al. (2004) mostrou resultados coerentes com Gomide (2000) e Gomide e Speranceta (2002). Nesses estudos o efeito da exposição a filme violento foi testado através do enredo de uma redação. As crianças de ambos os sexos apresentaram grande conteúdo de agressividade em seus enredos após terem assistido a um filme de luta. Nesse caso, o estudo mostra que a exposição a modelos comportamentais inadequados pode influenciar diretamente os conteúdos simbólicos manifestos, que podem ser indicadores de como as crianças atribuem sentido às suas experiências. Essa atribuição de sentido às experiências parece ser ponto central na construção dos padrões interpretativos da realidade que poderão influenciar suas futuras emoções e comportamentos (Beck, 1997).

Watson e Peng (1992) incluíram a observação de conteúdos simbólicos apresentados em situações lúdicas e verificaram uma relação entre exposição a modelos de comportamento agressivo envolvendo armas e a subseqüente aparição de conteúdos simbólicos agressivos.

Resultado semelhante aos já citados acima foi encontrado em um estudo realizado na Espanha, onde crianças pré-escolares assistiram a um vídeo de dez minutos, mostrando uma tourada tradicional (Graña et al., 2004). O mesmo vídeo foi copiado três vezes, cada cópia com uma narração diferente. Em um deles a narração era neutra e em outra era festiva (que apresentava as cenas como algo divertido, tal como se narra um jogo de futebol, por exemplo). Uma terceira narração ressaltava os perigos e a dor envolvidos na situação, descrevendo as consequiências negativas das atitudes dos personagens (sangue, dor, iminência de morte, etc.). Crianças que assistiram ao vídeo com narrativa festiva mostraram agressividade significativamente elevada, enquanto a exposição ao vídeo que ressaltava a agressividade e suas conseqüências demonstrou grande impacto psicológico, resultando também em baixa tolerância diante da agressividade. As crianças que viram o vídeo com narração festiva mostraram insensibilidade às conseqüências dolorosas sofridas pelos personagens na ação e escores mais elevados em testes de auto-observação da agressividade.

É interessante observar que o estudo espanhol incluiu a mediação de uma interpretação cognitiva do modelo e seu efeito sobre o observador. Isso pode indicar que a forma como a violência é apresentada (de forma festiva, cômica, justificável, ou mesmo como algo louvável), podem ser fatores importantes na diminuição da sensibilidade à dor alheia. Mais do que isso, esse tipo de mediação pode influenciar a formação de fantasias de heroísmo e vingança e de um distorcido senso de justiça freqüentemente presente na mídia de entretenimento.

\section{Ambientes Sociais Inadequados e o Desenvolvimento de Psicopatologias}

Apesar dos dados que sugerem fortes influências do meio-ambiente familiar e da mídia na formação inadequada dos jovens atiradores, é importante evitar explicações deterministas. Cada um dos fatores identificados deve ser compreendido como parte de uma complexa rede de variáveis, boa parte delas de origem social. Stephen Thompson e Ken Kyle (2005) afirmam que ao invés de nos preocuparmos com traços que compõem os perfis dos atiradores, devemos nos preocupar com os perfis dos meios onde os massacres ocorrem e como estudantes despreparados para tais ambientes podem responder aos mesmos. Olhando o fenômeno a partir desse ângulo, Clabaugh e Clabaugh (2005) chamaram a atenção para a configuração das interações sociais presentes em Columbine antes do massacre.

Segundo Clabaugh e Clabaugh (2005) após cada tragédia nos Estados Unidos alguns psiquiatras e psicólogos clínicos, vários deles ligados ao Federal Bureau of Investigation (FBI), apresentam relatórios sobre o perfil 
psicológico dos assassinos, destacando características de personalidade e psicopatologias. Não raro, rótulos assim provocam uma série de problemas de discriminação e de procedimentos constrangedores por parte de escolas, criando um ambiente tenso e gerando ainda mais complicações para alguns indivíduos que passam a ser identificados como socialmente inaptos e assassinos em potencial. Para Killingbeck (2001), medidas drásticas de segurança acabam gerando mais problemas e provocando uma percepção distorcida por parte da população que compreende as tragédias através da mídia. Revistas em estudantes em busca de armas, policiamento dentro das escolas e mesmo o aparecimento de empresas especializadas em segurança nas escolas, segundo Killingbeck (2001), não têm ajudado a evitar as tragédias. Frente às informações que recebem pela mídia, a população pode superestimar o risco de morte que as crianças e adolescentes correm nas escolas. De acordo com Harding et al. (2002), os Rampage School Shootings são eventos raros e representam um percentual muito baixo no rol de causas de mortes de crianças e adolescentes em geral, e mesmo de crianças e adolescentes na escola. Essa afirmação não diminui a relevância do estudo do fenômeno, mas alerta sobre os perigos de percepções distorcidas do mesmo, que podem reforçar a justificativa de medidas extremas.

Não se deve deixar de observar, entretanto, que as opiniões dos psicólogos e psiquiatras que enfatizam a construção do perfil psicológico dos atiradores, mesmo sendo alguns deles ligados ao FBI, não representam a opinião de todas as agências norte-americanas. Um relatório detalhado apresentado pelo Serviço Secreto dos Estados Unidos em parceria com o Departamento de Educação dos Estados Unidos (United States Secret Service \& United States Department of Education, 2004) revisou mais de 30 episódios (entre massacres e tentativas), buscando compreender o fenômeno e desenvolver possíveis propostas de prevenção. O relatório afirma que não há um perfil característico dos estudantes atiradores (nem psicológico nem demográfico), pelo menos não de forma acurada. Chama a atenção, todavia, o fato do relatório não descartar que há variáveis que podem ser identificadas em boa parte dos incidentes desta natureza. Dentre estas, ressaltam-se a dificuldade dos atiradores em lidar com perdas significativas e falhas pessoais, interesse por mídia violenta (filmes, jogos, livros e outros), o fato de terem sido ou estarem sendo vítimas de perseguições e humilhações de colegas, a manifestação de comportamentos anteriores que sinalizavam que eles precisavam de ajuda, dentre outros.

Clabaugh e Clabaugh (2005) apontam o procedimento dos psicólogos e psiquiatras que tentam explicar o fenômeno a partir do perfil psicológico dos atiradores como um erro de atribuição. Para os autores as tragédias devem ser analisadas dentro de uma rede causal que se desenvolve principalmente no meio-ambiente social, sendo que psicopatologias podem se desenvolver (ou se potencializar) em decorrência de fatores ambientais. Clabaugh e Clabaugh (2005) comparam o ambiente da escola de Columbine com aquele criado e conduzido experimentalmente pelo psicólogo social Phillip Zimbardo na Stanford University em 1971. No experimento, pessoas consideradas psicologicamente saudáveis foram colocadas numa situação onde desempenhavam papéis de guardas ou prisioneiros (Haney, Banks, \& Zimbardo, 1973).

$\mathrm{O}$ experimento de Zimbardo precisou ser interrompido após seis dias, pois os participantes começaram a apresentar comportamentos patológicos e perda do senso de realidade; a tensão entre prisioneiros e guardas levou a uma escalada de abusos e violência, incorrendo na possibilidade de riscos sérios para todos, inclusive para os próprios experimentadores. Todavia, para compreensão da comparação entre o experimento de Zimbardo e a situação em Columbine, faz-se necessário descrever o ambiente da escola de acordo com um artigo publicado pelo jornal Washington Post em 12 de Junho 1999, ao qual se refere o artigo de Clabaugh e Clabaugh (2005).

Escrito por Lorraine Adams e Dale Russakoff (1999), e intitulado "Dissecting Columbine's Cult of the Athlete" (Dissecando o Culto ao Atleta em Columbine), o artigo descreve o ambiente social da escola. Columbine era uma escola típica americana, onde os adolescentes que obtêm destaque nos esportes são muito populares. Muito mais do que popularidade, os atletas na Columbine "pré-massacre" desfrutavam de privilégios e da proteção de técnicos, professores e diretores. Segundo os relatos, nem todos, mas vários atletas tinham por hábito a prática do bullying contra alunos pouco populares, incluindo Erick Harris e Dylan Klebold.

De acordo com Espelage e Swearer (2003), não existe uma única definição para o bullying; ainda assim, a maioria dos autores concorda que essa prática é marcada por agressões físicas ou verbais (ofensas, humilhações, ridicularizações, etc.) que persistem ao longo do tempo, em uma relação onde há desequilíbrio de poder, ou seja, em que a vítima tem dificuldades em se defender (para mais informações, também verificar Burgess, Garbarino, \& Carlson, 2006).

O sociólogo americano Ralph W. Larkin (2007), em seu livro "Comprehending Columbine", discute o tema de forma coerente com a opinião de Clabaugh e Clabaugh (2005) e confirma a importância dos comportamentos dos atletas contra Harris, Klebold e outros alunos caracterizados como outsiders (diferentes dos estereótipos dos alunos populares). Para Larkin (2007), os principais fatores que influenciaram a ocorrência da tragédia foram: a vingança contra os atletas que os perseguiam e humilhavam, contra estudantes evangélicos que agiam como se fossem moralmente superiores, e também pela influência da cultura paramilitar norte-americana com- 
Vieira, T. M., Mendes, F. D. C. \& Guimarães, L. C. (2009). De Columbine à Virgínia Tech: Reflexões com Base Empírica sobre um Fenômeno em Expansão.

binada a um desejo de notoriedade que poderia ser alcançado através de uma morte gloriosa.

\section{Reflexões Gerais}

Reflexões embasadas por dados empíricos sobre os ocorridos em Columbine e Virginia Tech podem ser úteis na compreensão do fenômeno como um todo e para a sua prevenção. Essas duas tragédias foram tomadas de exemplo por serem as mais expressivas até os dias atuais, tanto em número de vítimas como em destaque recebido na mídia mundial.

Primeiramente, tem-se notado uma preocupação imediata após os massacres em se eximir as famílias dos atiradores de qualquer tipo de culpa pelas tragédias. Isso é, por um lado, compreensível, já que o que se teme são represálias contra familiares; por outro lado, isso tem contribuído com a preferência por atribuições de causalidade a fatores internos dos próprios atiradores (psicopatologias e características de personalidade). Contudo, Eva Fjällström (2007) considera que em cada massacre há sempre uma família responsável. Isso não implica dizer que as famílias são as "causas" das tragédias, mas que têm participação importante. A mesma autora lembra que em uma entrevista coletiva para a imprensa, o investigador responsável pelo trabalho policial em Columbine declarou que os pais dos adolescentes atiradores eram pessoas dóceis, amáveis, e não os monstros que se poderia imaginar; mas, uma análise cuidadosa dos vídeos gravados pelos adolescentes é bastante reveladora.

Nos vídeos os adolescentes mostram remorso em relação aos pais, pedem pelo perdão e afirmam que eles são bons pais e em nada poderiam ter evitado a tragédia. Porém, os relatos dos adolescentes são contraditórios, pois as evidências apontam para pais indulgentes que, apesar de manterem um relacionamento afetivo aparentemente positivo com os filhos, não os monitoravam, e sequer estabeleciam limites e orientações significativas (Cecconello et al., 2003). Isso complexifica a análise, ao levantar a suspeita de que a manutenção do afeto positivo, em si, não é contribuição suficiente dos pais para o desenvolvimento dos filhos (apesar de necessária). O monitoramento, estabelecimento de limites e orientações claras, parece ser imprescindível. Uma forte evidência disso são as descrições que aparecem nos vídeos, das armas e bombas que os adolescentes guardavam em seus próprios quartos, de forma absurdamente fácil de serem encontradas (Fjällström, 2007). Para Fjällström (2007) o que os adolescentes chamam de bons pais pode significar exatamente essa distância. De acordo com a autora, para um adolescente é muito comum que o mais desejado seja que os pais não interfiram em suas rotinas, isto é, que os "deixem em paz". Em uma das fitas, Erick Harris imagina uma possível reação de sua mãe após o massacre, da seguinte forma: "Se nós simplesmente tivésse- mos procurado em seus quartos! Se nós tivéssemos simplesmente feito as perguntas certas!" (Fjällström, 2007, p. 20).

Muito mais do que descobrir as armas e bombas, os pais parecem ter falhado em perceber que os filhos sofriam humilhações no ambiente escolar e com isso alimentavam insatisfação e ideações de violência, vingança e suicídio.

Quanto à influência da mídia sobre o comportamento de Harris e Klebold, houve bastante alarde acerca de sua preferência por filmes e videogames violentos e pelo gosto por música de protesto, especialmente Marilyn Manson. Os filmes e videogames de fato podem ter contribuído na construção das fantasias de vingança e de uma morte gloriosa e heróica, tal como discutido por Killingbeck (2001) e Larkin (2007), o que parece ter sido reforçado pela própria cultura paramilitar norte-americana e o fácil acesso a armas e munição. É razoável considerar tais fatores como possivelmente relacionados aos comportamentos extremos dos atiradores de Columbine, mas eles também não podem ser apontados como causas determinantes.

Da mesma forma, o gosto pela música de Marilyn Manson pode ter uma relação com o descontentamento da parte dos dois jovens atiradores em relação aos estudantes evangélicos e sua possível atitude de arrogância moral. A música de Marilyn Manson é caracterizada por conteúdos de protesto contra o modo de vida americano e violenta oposição ao cristianismo. Vale ponderar que, da mesma forma que os adolescentes construíram uma concepção distorcida de justiça e heroísmo sob influência de entretenimento violento e da indignação contra pessoas do seu meio, também podem ter interpretado as atitudes dos estudantes evangélicos de forma distorcida sob influência do conteúdo das músicas. Esse argumento ajuda na reflexão sobre a forma como tais adolescentes construíram um sistema de crenças específico. O sistema de crenças se refere a um conjunto de padrões interpretativos sobre a vida, as situações e as pessoas, bem como sobre a forma de se verem diante de um mundo injusto no qual eles se percebiam como discriminados e perseguidos (Beck, 1997). Portanto, seria imprudente apontar tanto Marilyn Manson como os estudantes evangélicos como culpados pela tragédia. Mas, o fato de tais conteúdos (música, cinema, jogos eletrônicos) serem apresentados a partir de um viés de entretenimento, de acordo com Graña et al. (2004), também é importante para a compreensão de como os adolescentes desenvolveram suas percepções da realidade e ideações de vingança (ou de como isso pode ter sido potencializado).

Por último, parece incontestável a importância do histórico de perseguição sofrido por Harris e Klebold. Os relatos obtidos por Adams e Russakoff (1999) mostram que ao entrar no refeitório os atiradores pediram, antes

${ }^{1}$ No original: "If only we would have searched their room. If only we would have asked the right questions". 
de começar a atirar, que todos os atletas ficassem de pé (Clabaugh \& Clabaugh, 2005). Tudo indica que planejavam atirar primeiro nos atletas.

No caso de Cho Seung-Hui há que se considerar o fato do rapaz ter sido um estrangeiro (sul-coreano) pertencente a uma classe social que não lhe permitia acesso ao padrão de consumo predominante nos Estados Unidos. Em um bilhete encontrado depois da tragédia, Cho faz declarações de ódio contra o que ele chamou de "meninos ricos". Todavia, os relatos de ex-colegas e outras pessoas de que Cho era uma pessoa inteligente, mas extremamente tímida e solitária, chama a atenção (Marques, 2007). O histórico de segregação e humilhações sofridas no ambiente escolar parece ser muito mais significativo.

Uma análise mais cuidadosa do meio e das relações de Cho revela que ele sofreu constantes humilhações ao longo da sua experiência escolar, especialmente na adolescência, devido às dificuldades de pronúncia em língua inglesa e sua timidez. Há relatos de ex-colegas de classe que apontam que algumas pessoas eram especialmente cruéis, colocando apelidos constrangedores e provocando situações humilhantes. Apesar do próprio modo solitário de ser do rapaz ter acentuado as críticas e perseguições dos colegas, parece haver uma dinâmica cíclica entre as humilhações e a sua timidez. As humilhações parecem ter contribuído para o isolamento de Cho e comportamentos considerados estranhos por alguns colegas. Em seu isolamento, o rapaz parece ter nutrido fantasias de vingança, se inspirando no evento de Columbine, o que é citado pelo próprio Cho em seu vídeo enviado a NBC (Marques, 2007).

Nas fotografias deixadas por Cho Seung-Hui há imitações de cenas do filme "Oldboy" (2003) do diretor sul-coreano Chan-wook Park e dos produtores Dong-joo e Young-joon. $O$ filme tem como temática principal a vingança, o que pode ter influenciado na construção de fantasias de vingança e heroísmo. Contudo, a participação da mídia não parece advir apenas dos filmes de ação, mas também da própria mídia jornalística que repetiu durante anos os detalhes da tragédia de Columbine, contribuindo assim para que os objetivos de Harris e Klebold fossem atingidos. Nas declarações de Cho Seung-Hui, Harris e Klebold aparecem como mártires e ele revela o desejo de alcançar a mesma "glória".

Outra consideração importante é que o chamado de Cho Seung-Hui para que novos massacres sejam realizados pode não ter efeito para a maioria dos adolescentes vítimas nas escolas, de modelos parentais inadequados e que se expõem a mídia violenta; mas não se pode negar o risco de que isso influencie novos massacres ao redor do mundo. À medida que a divulgação de tais informações se torna mais globalizada (apresentada em mais países), cresce também o risco de que o fenômeno se repita em qualquer outro país (tal como vem acontecendo). Além da influência da divulgação irrestrita da tragédia de Columbine presente nas declarações de Cho, é importante destacar a data escolhida pelo rapaz para executar o massacre na Virginia Tech. O dia escolhido foi exatamente à véspera do oitavo aniversário da tragédia de Columbine. Isso mostra também características do fenômeno conhecido como copycat.

$\mathrm{O}$ efeito copycat se refere a assassinatos inspirados por outros acontecidos anteriormente (McGee \& DeBernardo, 1999). De acordo com McGee e DeBernardo (1999) esse fenômeno tem sido observado com certa freqüência e pode ser bem ilustrado no tiroteio ocorrido poucos dias após o massacre de Columbine, em uma escola do Canadá: um adolescente de 14 anos entrou atirando pela escola, matando uma pessoa e ferindo várias outras. $\mathrm{O}$ adolescente canadense vestia roupas semelhantes às que Harris e Klebold vestiam no dia do massacre de Columbine e apresentou outros indícios de tal inspiração.

Tanto em Columbine como na Virginia Tech, práticas de humilhação contra pessoas classificadas como outsiders (excluídas) estavam presentes. Em ambos os casos a prática de bullying e a falta de interesse e/ou competência de pais, professores, diretores e colegas para se aproximar dos adolescentes e tentar alguma intervenção é marcante. Se Harris e Klebold compraram armas e fabricaram bombas, guardando o arsenal em casa sem sequer despertar a desconfiança dos pais ou qualquer pessoa próxima, com Cho Seung-Hui não foi diferente. O estudante sul-coreano comprou pistolas e munição em quantidade suficiente para disparar mais de 100 tiros, gravou vídeos e fotografou-se com as armas nas mãos, sem despertar nenhuma suspeita. Ninguém estava próximo o suficiente para perceber as armas e planos do rapaz, ou para compreender os motivos do seu isolamento e sua indignação.

Chamando a atenção para os locais das tragédias, Thompson e Kyle (2005) consideram que em meios altamente competitivos como o escolar (competitivo em vários sentidos, como, por exemplo, nas disputas por popularidade e auto-afirmação), alguns indivíduos são sempre segregados. Ao serem segregados, são privados de importantes interações sociais necessárias para o desenvolvimento de uma filosofia moral (noções acerca do certo e do errado, das normas sociais de convivência, dos limites e necessidades dos outros, etc.). Quando emerge o senso de significância e a necessidade de se expressarem, isso pode ocorrer através de meios inadequados de expressão, tal como a violência (e algumas vezes a violência extrema). Essa opinião também é compartilhada, em discussão similar, por Marques (2007).

Voltando à concepção de Urie Bronfenbrenner (1996), é necessário lembrar que o início desse importante processo de desenvolvimento de competências sociais se dá nas primeiras interações (pai-filho, mãe-filho, irmãoirmão, colega-colega, professor-criança, etc.). Isso reforça o argumento de que as competências sociais de um indivíduo adolescente e mesmo adulto dependem, pelo menos em certo grau, de oportunidades anteriores (Bron- 
Vieira, T. M., Mendes, F. D. C. \& Guimarães, L. C. (2009). De Columbine à Virgínia Tech: Reflexões com Base Empírica sobre um Fenômeno em Expansão.

fenbrenner, 1996; Martins \& Szymanski, 2004). Assim, perguntas a respeito das oportunidades que Harris, Klebold, Cho e outros atiradores tiveram no convívio familiar e escolar, são de grande relevância.

A presença de pais atuantes e reflexivos no cotidiano dos filhos pode contribuir para que modelos de vingança e interpretações distorcidas de atos heróicos violentos sejam questionados e modelos adequados sejam construídos e apresentados aos filhos. Da mesma forma, pais presentes, que interagem e se dedicam afetivamente aos filhos têm condições de identificar que tipo de relações eles vêm estabelecendo em seu cotidiano (Há sinais de que possam estar sendo vítimas de bullying? Há carência de afeto?), de identificar elementos de risco (interesses por armas, textos, vídeos, e materiais que possam influenciar a construção de percepções distorcidas da realidade), e assim proceder com as intervenções e cuidados pelos quais são responsáveis.

Se no Brasil ainda não há relatos de tragédias com as mesmas configurações de Columbine e Virginia Tech, outras formas de violência têm sido observadas no contexto escolar, relacionadas, também, aos fatores aqui discutidos. Os tipos mais comuns são depredações do patrimônio e agressão interpessoal (Abramovay, 2002). $\mathrm{O}$ porte de armas de fogo e armas brancas tem sido relatado com muita freqüência em escolas brasileiras, muitas vezes resultando em ferimentos graves e mortes nos conflitos entre estudantes.

No Brasil, o problema da pobreza e o tráfico de drogas aparecem entre os fatores mais freqüentemente apontados como diretamente relacionados à violência na escola. Contudo, vários autores que analisaram o problema da violência escolar no contexto brasileiro concordam que, também no Brasil, o ambiente familiar se mostra significativo tanto na prevenção da violência como em políticas de intervenção (Abramovay, 2002; Njaine \& Minayo, 2003; Sposito, 2001; Williams \& Pereira, 2008).

Apesar de haver fatores de natureza distinta na realidade brasileira e em outras culturas diferentes da cultura norte-americana, a divulgação das tragédias de Columbine e Virginia Tech ganhou destaque intenso em todo o mundo. Além disso, os dados apresentados e discutidos por Cecconello et al. (2003), Marler et al.(2005) e Vieira (2007), dentre os vários outros artigos já citados, são válidos para explicar não apenas o fenômeno school shooting, mas se aplicam a vários outros problemas comportamentais e outras formas de comportamento violento.

Diante dos argumentos aqui apresentados, então, é razoável considerar que um massacre em uma escola ou universidade deve ser visto como o trágico desfecho de um longo processo que pode ter se iniciado nas primeiras interações sociais e se desdobrado pelos anos de escola e universidade. Portanto, concordando com Marques (2007), é um equívoco rotular um estudante atirador simplesmente como um "psicopata tresloucado" impulsionado a matar.
O presente artigo não tem como objetivo descartar a importância de psicopatologias, mas alerta para evidências como as apresentadas por Clabaugh e Clabaugh (2005) e no próprio trabalho de Phillip Zimbardo, de que pessoas psicologicamente saudáveis podem pensar e se comportar de forma patológica quando perseguidas, abusadas, abandonadas e discriminadas. Da mesma forma, podem se comportar de forma abusiva quando lhes são dados poderes para agir como quiserem, sem limites para tal. Se em apenas seis dias, em uma situação experimental, os participantes do experimento de Zimbardo passaram a se comportar de forma cada vez mais abusiva (guardas) contra outros (prisioneiros), é possível deduzir o quão perigoso se tornou o ambiente de Columbine (e como podem ser perigosos vários outros ambientes, inclusive escolas brasileiras onde alunos ameaçam colegas e professores com armas, impunemente). Em Columbine, assim como ao longo da história escolar de Cho Seung-Hui, as humilhações e abusos duraram por um período longo (anos), e não apenas por alguns dias. Há relatos de que tanto em Columbine como na Virginia Tech, o ambiente da escola era altamente competitivo e marcado pela prática do bullying e pela falta de efetividade de professores e diretores para intervir (Marques, 2007; Muschert, 2007; Thompson \& Kyle, 2005).

Por último, como o presente artigo também objetiva incentivar a pesquisa sobre o desenvolvimento de comportamentos violentos no Brasil e em outros países onde o fenômeno school shooting ainda não ocorreu, vale atentar com cuidado ao trabalho de Harding et al. (2002). O artigo trata da dificuldade de se estudar eventos raros e utiliza como exemplos casos de rampage school shootings. Para os autores, o primeiro desafio é definir o universo de casos que podem realmente ser chamados de rampage school shootings. Muitos tipos diferentes de tiroteios podem ocorrer no ambiente da escola, por motivos diferentes (de origem passional, roubos ou enfrentamento entre estudantes por motivos diferentes daqueles apresentados pelos atiradores, por exemplo). Outra dificuldade, relacionada à primeira, se dá na necessidade de também estudar a não ocorrência do evento, isto é, comparar atiradores com não atiradores que freqüentam as mesmas escolas e comunidades. Essa comparação deve ocorrer em vários níveis de análise, partindo de indivíduos, famílias e comunidades, e atingindo um nível macro envolvendo países (comparando, por exemplo, países onde muitos casos ocorreram, como os Estados Unidos, com países onde o fenômeno ainda não ocorreu).

Para Harding et al. (2002), o foco apenas em fatores presentes quando os eventos ocorrem, não ajudam a identificar quais as condições suficientes para a ocorrência do fenômeno. Outra grande dificuldade se dá quando há um grande número de possíveis causas e um número muito pequeno de ocorrência dos eventos em questão. No caso dos rampage school shootings, as causas mais apontadas são: a disponibilidade de armas de fogo, mídia 
violenta, problemas familiares, a cultura ocidental da violência, bullying e outros; no entanto, tais fatores se apresentam com uma freqüência notavelmente muito mais elevada do que o número de tiroteios já registrados. Além disso, outra dificuldade se dá no fato de que não é possível isolar as causas, já que elas parecem se combinar de forma muito complexa. Outras dificuldades são consideradas, aumentando a complexidade, como por exemplo, a observação de diferentes causas para eventos muito semelhantes e que podem ser categorizados como rampage school shootings. Como um bom exemplo disso, citam-se casos de tiroteios em que há clara manifestação do efeito copycat e outros em que tal efeito não aparece.

Apesar de apontar as dificuldades para estudo de fenômenos raros, Harding et al. (2002) incentivam a investigação dos mesmos e propõem uma teoria com base em cinco fatores que são admitidos como necessários, mas não suficientes para a ocorrência de rampage school shootings. O primeiro fator é a disponibilidade de armas. O segundo fator é o suporte de uma cultura onde o atirador desenvolve crenças que o ajudam a justificar o uso de uma arma como meio aceitável para a solução de algum problema que ele considera importante o suficiente para chegar a tal extremo. Um terceiro fator, também relacionado ao desenvolvimento das crenças do indivíduo, diz respeito à percepção do mesmo de posições sociais que lhe parecem importantes em seu meio e das quais ele foi privado ao longo de um processo de marginalização. Acontecimentos marcantes da vida do indivíduo (rompimentos familiares, abusos, perdas, etc.), bem como possíveis psicopatologias, aparecem como o quarto fator. Todavia, os autores deixam claro que o quarto fator é importante, basicamente, por aumentar a vulnerabilidade aos outros fatores. O quinto fator é apontado pelos autores como sendo a falha dos sistemas de suporte social que poderiam atender aos adolescentes problemáticos antes que seus problemas se tornassem tão extremos a ponto de levá-los a protagonizar um massacre.

A discussão apresentada por Harding et al. (2002) ressalta a necessidade de mais pesquisa e, ao mesmo tempo, mostra a fragilidade de explicações deterministas para o fenômeno. $\mathrm{O}$ uso do princípio de que há condições necessárias e suficientes para a ocorrência de fenômenos complexos é de grande valia por ajudar na identificação de fatores de risco que deixam em aberto a possibilidade da prevenção. Os fatores apresentados pelos autores abrem a possibilidade para que educadores, famílias, e gestores em geral trabalhem na construção de medidas preventivas.

Por último, é importante comentar que o viés reflexivo aqui assumido pode ser interpretado de forma valorativa por parte do grande público e mesmo por parte de alguns cientistas. Muitos consideram que explicações focadas em fatores externos ao indivíduo têm o objetivo de eximi-los da culpa pelas tragédias que provocaram. Esse não é o objetivo deste artigo. Não há nenhuma justificativa possível para os atos de Erick Harris, Dylan Klebold, Cho Seung-Hui ou para qualquer protagonista de atos de violência. Todavia, o papel dos cientistas não é atribuir culpa ou eximir indivíduos de culpa, mas sim apresentar dados e explicações que contribuam para a compreensão do fenômeno e, possivelmente, para a construção de prevenções a partir dos fatores de risco.

A relevância do estudo dos fatores aqui apresentados não se limita ao fenômeno dos tiroteios nas escolas. Ambientes que proporcionem oportunidades de interações adequadas podem ajudar na prevenção do desenvolvimento de padrões comportamentais inadequados e de muitas outras formas de manifestação da violência. Por outro lado, isso não exclui a necessidade de que um alerta seja dado quanto às possibilidades de expansão de um fenômeno tão impactante e com perdas tão significativas como o school shooting. O alerta aqui apresentado é válido em todo o planeta, mesmo em países onde não há nenhum registro do fenômeno, pois as condições necessárias, mesmo que não suficientes, são observadas em todo o mundo.

\section{Referências}

Abramovay, M. (2002). Escola e violência. Brasília, DF: Organização das Nações Unidas para a Educação, a Ciência e a Cultura.

Adams, L., \& Russakoff, D. (1999, June 12). Dissecting Columbine's cult of the athlete. The Washington Post, p. A1.

Alves, L. R. G. (2004). Game over: Jogos eletrônicos e violência. Tese de Doutorado não-publicada, Universidade Federal da Bahia, Salvador, BA.

Anderson, C. A., \&, Bushman B. J. (2002). The effects of media violence on society. Science, 295, 2377-2379.

Bandura, A. (1979). Modificação do comportamento. Rio de Janeiro, RJ: Interamericana.

Barr, R., \& Hayne, H. (2003). It's not what you know, it's whom you know: Older siblings facilitate imitation during infancy. International Journal of Early Years Education, 11, 7-21.

Batista, A. P., Fukahori, L., \& Haydu, V. B. (2004). Filme com cenas de violência: Efeito sobre o comportamento agressivo de crianças expresso no enredo de uma redação. Interação em Psicologia, 8(1), 89-102.

Beck, J. S. (1997). Terapia cognitiva: Teoria e prática. Porto Alegre, RS: Artmed.

Bronfenbrenner, U. (1996). A ecologia do desenvolvimento humano: Experimentos naturais e planejados. Porto Alegre, RS: Artes Médicas.

Burgess, A.W., Garbarino, C., \& Carlson, M. I. (2006). Pathological teasing and bullying turned deadly: Shooters and suicide. Victims and Offenders, 1(1), 1-14.

Cecconello, A. M., Antoni, C., \& Koller, S. H. (2003). Práticas educativas, estilos parentais e abuso físico no contexto familiar. Psicologia em Estudo, 8, 45-54.

Clabaugh, G. K., \& Clabaugh, A. A. (2005). Bad apples or sour pickles? Fundamental attribution error and the Columbine massacre. Educational Horizons, 83(2), 81-86. 
Vieira, T. M., Mendes, F. D. C. \& Guimarães, L. C. (2009). De Columbine à Virgínia Tech: Reflexões com Base Empírica sobre um Fenômeno em Expansão.

Espelage, D. L., \& Swearer, S. M. (2003). Research on school bullying and victimization: What have we learned and where do we go from here? School Psychology Review, 32(3), 365383.

Fjällström, E. (2007). The high school shooting at Columbine seen from Francie Brady's perspective. Unpublished bachelor tesis, Lulea University of Technology, Lulea, Sweden.

Gomide, P. I. C. (2000). A influência de filmes violentos em comportamento agressivo de crianças e adolescentes. Psicologia: Reflexão e Crítica, 13(1), 1-22.

Gomide, P. I. C., \& Speranceta, A. (2002). O efeito de um filme de abuso sexual no comportamento agressivo de adolescentes. Interação em Psicologia, 6(1), 1-11.

Graña, J. L., Cruzado, J. A., Andreu, J. M., Muñoz-Rivas, M. J., Peña, M. E., \& Brain, P. F. (2004). Effects of viewing videos of bullfights on Spanish children. Aggressive Behavior, 30(1), 16-28.

Haney, C., Banks, W. C., \& Zimbardo, P. G. (1973). Study of prisoners and guards in a simulated prison. Naval Research Reviews, 9, 1-17.

Harding, D. J., Fox, C., \& Mehta, J. D. (2002). Studying rare events through qualitative case studies: Lessons from a study of rampage school shootings. Sociological Methods \& Research, 31(2), 174-217.

Killingbeck, D. (2001). The role of television news in the construction of school violence as a "moral panic". Journal of Criminal Justice and Popular Culture, 8(3), 186-202.

Larkin, R. W. (2007). Comprehending Columbine. Philadelphia, PA: Temple University Press.

Lickel, B., Schmader, T., \& Hamilton, D. L. (2003). A case of collective responsibility: Who else was to blame for the Columbine high school shootings? Personality and Social Psychology Bulletin, 29(2), 194-204.

Lima, M., \& Zakabi, R. (1999, 11 nov.). O horror fora da tela. Veja, 623. Retrieved November 8, 2008, from http:// veja.abril.com.br/101199/p_038.html

Marler, C., Trainor. B. C., \& Davis, E. (2005). Paternal behavior and offspring aggression. Current Directions in Psychological Science, 14(3), 163-166.

Marques, R. (2007). Virginia Tech: Anatomia de um massacre à luz da ética da virtude. Interacções, 5, 72-81.

Martins, E., \& Szymanski, H. (2004). A abordagem ecológica de Urie Bronfenbrenner em estudos com famílias. Estudos e Pesquisas em Psicologia, 4(1), 63-77.

McGee, J. P., \& DeBernardo, C. R. (1999). The classroom avenger. The Forensic Examiner, 8(5), 1-16.

Moore, M. (Director), \& Bishop, C. (Producer). (2002). Tiros em Columbine [Motion picture]. United States: K. Engfehr.

Muschert, G. W. (2007). Research in school shooting. Sociology Compass, 1(1), 60-80.

Njaine, K., \& Minayo, M. C. S. (2003). Violência na escola: Identificando pistas para a prevenção. Interface - Comunicação, Saúde, Educação, 7(13), 119-134.

Park, C. (Director), Dong-joo, K., \& Young-joon, J. (Producers). (2003). OldBoy [Motion picture]. Coréia do Sul: K. Sangbum.

Ramage, S. (2007, April). Why? After a heartbreaking tragedy at Virginia Tech, some experts offer answers. The Sunday Paper, p. 1-4. Retrieved December 01, 2008, from http:// www.sundaypaper.com/More/Archives/tabid/98/articleType/ ArticleView/articleId/2/Why.aspx

Sposito, M. P. (2001). Um breve balanço da pesquisa sobre violência escolar no Brasil. Educação e Pesquisa (São Paulo), 27(1), 87-103.
Thompson, S., \& Kyle, K. (2005). Understanding mass school shootings: Links between personhood and power in the competitive school environment. The Journal of Primary Prevention, 26(5), 419-438.

United States Secret Service., \& United States Department of Education. (2004). The final report and findings of the safe school initiative: Implications for prevention of school attacks in the United States. Washington, DC: Authors.

Vieira, T. M. (2007). Fatores de aprendizagem social, comportamento agressivo e comportamento lúdico de meninos pré-escolares. Dissertação de Mestrado não-publicada, Universidade Católica de Goiás, Goiânia, GO.

Watson, M. W., Andreas, J. B., Fischer, K. W., \& Smith, K. (2005). Patterns of risk factors leading to victimization and aggression in children and adolescents. In K. A. KendaallTackett \& S. M. Giacomoni (Eds.), Child victmization: Maltreatment, bullying and dating violence: Prevention and intervention. (pp. 12.1-12.23). Kingston, NJ: Civic Research Institute.

Watson, M. W., \& Peng, Y. (1992). The relation between toy gun play and children's aggressive behavior. Early Education and Development, 3(4), 370-389.

Williams, L. C. A., \& Pereira, A. C. S. (2008). A associação entre violência doméstica e violência escolar: Uma análise preliminar. Educação: Teoria e Prática, 18(30), 25-35.

Zavaschi, M. L. S. (Ed.). (1998). A televisão e a violência: Impacto sobre a criança e o adolescente. Retrieved November 11, 2006, from http://www.ufrgs.br/psiq/cip.html
Recebido: 17/10/2007 $1^{a}$ revisão: 07/10/2008 $2^{a}$ revisão: $21 / 11 / 2008$

$3^{a}$ revisão: 04/12/2008 Aceite final: 04/12/2008 